\title{
The Study of Maternal and Neonatal Outcome of Primary Cesarean Section at Term - Influence of Labour and Stage
}

\author{
Dr. T. Shobha ${ }^{1}$, Dr. Jyothi ${ }^{2}$ \\ ${ }^{1}$ Associate Professor Modern Government Maternity Hospital, Petlaburz \\ Department Of Obstetrics and Gynaecology, Osmania Medical College, Hyderabad - Telangana. \\ ${ }^{2}$ Post Graduate, Gandhi Hospital, Department of Obstetrics and Gynaecology, Gandhi Medical College, Hyderabad - Telangana
}

\begin{abstract}
Aim: To study the maternal Morbidity and Mortality associated with cesarean section which was done in first stage and second stage of Labour. And to study the Morbidity and Mortality in neonates delivered by Emergency cesarean section which was done in first stage and second stage of Labour. Materials and Methods: This observational cross sectional study was conducted in Gandhi Hospital, Secunderabad from June 2010-Oct 2012 in the department of Obstetricesarean section and Gyneacology. 200 antenatal women admitted through outpatient department and through Labour room underwent primary cesarean section were included in the study. Results: Out of 200 women, 184 women underwent cesarean section in first stage of Labour and 16 women underwent cesarean section in second stage of Labour. Fetal distress(38.04\%) was most common indication for section done in first stage of labour due to more number of inductions.Most common indication for cesarean section done in second stage of labour was undiagnosed CPD(56.25\%). Conclusion: Maternal morbidity and Perinatal morbidity, mortality was more in sections done in Second stage than in first stage of labour. Improvement of obstetrics services in periphery and use of partogram and early referral of cases can reduce the maternal and perinatal morbidity and mortality. Proper assessment of cases and cesarean section done at appropriate time can reduce maternal and perinatal mortality and morbidity.
\end{abstract}

Keywords: Emergency Lower Cesarean Section, Fetal distress, Malpresentations, Maternal morbidity.

\section{Introduction}

Cesarean section has been shown to be a safe operation ${ }^{1}$ and in many countries around the world there has been a dramatic increase in its frequency ${ }^{2-5}$. Cesarean section rate has been rising continuously and the trend is likely to continue in future. This increase has been a global phenomenon. The timing and rate of increase are different from one country to another. In 1970 the cesarean section rate in United Kingdom was reported to be $4.8 \%$. The audit commission report in 1997 found this rate increased to 11$18 \%{ }^{6}$. In England the rate was $21.3 \%^{7}$ and in Switzerland it was $29 \%^{8}$. A rate of $45 \%$ was reported in Puerto Rico between 1996 and $2002^{9}$. In medical colleges and teaching hospitals in India the overall rate of cesarean deliveries is $24.4 \%{ }^{10}$. In a population based cross sectional study the public, charitable and private sector hospitals had cesarean section rates of $20 \%, 38 \%, 47 \%$ respectively ${ }^{11}$.

In the19th century, mortality was almost $100 \%$, with the major causes being haemorrhage (from unsutured uterine wound) and infections. Aseptic and antiseptic methods with antibiotic therapy, use of blood transfusion and improved anaesthesia have all contributed to the dramatic decrease in mortality seen during the last century ${ }^{2}$.

Despite these improved results, considerable care is still required to maintain and improve the rates of maternal and perinatal morbidity and mortality. One-fourth of the primary cesarean sections are reported to be performed in the second stage of the labour ${ }^{12,13}$ and are more complicated compared to the ones performed in the first stage. The second stage of the labour can be defined as the time elapsed from full dilatation of the cervix to expulsion of the fetus. The extraction of the impacted head of the fetus from the maternal pelvis constitutes the main difficulty of the cesarean section in the second stage of labour and is associated with increased risks such as hemorrhage, prolonged operation time, and other intraoperative complications ${ }^{14}$. Neonatal mortality and morbidity due to hypoxia and fetal trauma remains to be one of the major issues regarding the cesarean sections performed in the second stages of labour ${ }^{13,15}$.

It has been recommended that the interval between a decision for caesarean section and the delivery in emergency cases should not exceed 30minutes ${ }^{16}$.

The cesarean section rate in our hospital is $38.48 \%$.This high cesarean section rate at our hospital is due to the more number of unbooked cases and complicated cases referred in late labour from periphery as it is a tertiary care teaching hospital. Among the total cesarean section cases the primary cesarean sections contribute to $60.62 \%$ and repeat cesarean sections contribute to $39.3 \%$

\section{Materials and Methods}

This observational cross sectional study was conducted in Gandhi Hospital, Secunderabad from June 2010-Oct 2012 in the department of Obstetricesarean section and Gyneacology. 200 antenatal women admitted through outpatient department and through Labour room underwent primary cesarean section were included in the study. 


\section{International Journal of Science and Research (IJSR) \\ ISSN (Online): 2319-7064 \\ Index Copernicus Value (2013): 6.14 | Impact Factor (2015): 6.391}

Primi, Multi gravida with previous normal vaginal deliveries older than 36 weeks of gestational age, malpresentations were included in the study. Preterm deliveries, multiple gestation and placenta previa were excluded from the study.

Out of 200 women, 184 women underwent cesarean section in first stage of Labour and 16 women underwent cesarean section in second stage of Labour, the time of full cervical dilatation was noted. Maternal age, gestational age, augmentation of Labour by oxytocin, pre operative investigations, pre operative vitals were recorded. For every case antibiotic prophylaxis was given half an hour before surgery.

I assisted all the discussed cases here and recorded the operative findings, Bladder complications, uterine complications, intra operative blood loss,. The patients were followed till discharge. Development of fever, Uterine Involution, Lochial discharge, Day of suture removal and healing of the wound were evaluated before discharge.

Baby delivery time, APGAR, weight, indication for NICU admission and duration also studied.

I compared outcome of cesarean section which was done in first stage and second stage of Labour.

Statistical analysis was done by Fisher's exact p test and chi - square test.

\section{Results}

Table 1: Incidence of Emergency Cesarean Section

\begin{tabular}{|c|c|c|c|}
\hline $\begin{array}{c}\text { S. } \\
\text { No. }\end{array}$ & $\begin{array}{c}\text { Stages of } \\
\text { Labour }\end{array}$ & $\begin{array}{c}\text { Total no. of cases } \\
\text { undergoing cesarean section }\end{array}$ & percentage \\
\hline 1. & $1^{\text {st }}$ stage & 184 & $92 \%$ \\
\hline 2. & $2^{\text {nd }}$ stage & 16 & $8 \%$ \\
\hline 3. & Total & 200 & $100 \%$ \\
\hline
\end{tabular}

Among 200 cases cesarean section done in first stage in $184(92 \%)$ patients and 16(8\%) were done in second stage.

Table 2: Indications For Emergency Section

\begin{tabular}{|c|c|c|c|c|c|}
\hline \multirow{2}{*}{$\begin{array}{c}\text { S. } \\
\text { No. }\end{array}$} & Indication & \multicolumn{2}{|c|}{$1^{\text {st }}$ stage } & \multicolumn{2}{|c|}{$2^{\text {nd }}$ stage } \\
\cline { 3 - 6 } & $\begin{array}{c}\text { No. of } \\
\text { cases }\end{array}$ & percentage & $\begin{array}{c}\text { No. of } \\
\text { cases }\end{array}$ & percentage \\
\hline 1. & Failure to progress & 42 & $22.8 \%$ & 3 & $18.7 \%$ \\
\hline 2. & Failed induction & 15 & $8.1 \%$ & Nil & Nil \\
\hline 3. & Oligohydraumnios & 18 & $9.7 \%$ & Nil & Nil \\
\hline 4. & Breech & 15 & $8.1 \%$ & Nil & Nil \\
\hline 5. & Transverse lie & 3 & $1.6 \%$ & Nil & Nil \\
\hline 6. & CPD & 14 & $7.6 \%$ & 9 & $56.25 \%$ \\
\hline 7. & Fetal distress & 70 & $38.04 \%$ & 3 & $18.7 \%$ \\
\hline 8. & Cord prolapse & 2 & $1.08 \%$ & Nil & Nil \\
\hline 10. & Brow & 1 & $0.54 \%$ & 1 & $6.25 \%$ \\
\hline 11. & Abruption & 4 & $2.17 \%$ & Nil & Nil \\
\hline
\end{tabular}

Most common indication for cesarean section in first stage was fetal distress in 70(38.04\%) cases.

Most common indication for cesarean section in second stage was CPD in 9(56.25\%) cases
Table 3: Intra Operative Complications In Emergency Cesarean Section

\begin{tabular}{|l|c|c|c|c|c|}
\hline S. & Type of & \multicolumn{2}{|c|}{ Cases of $1^{\text {st }}$ stage } & \multicolumn{2}{c|}{ Cases of 2 ${ }^{\text {nd }}$ stage } \\
\cline { 3 - 6 } No. & complication & Number & percentage & Number & Percentage \\
\hline 1. & $\begin{array}{c}\text { Bladder drawn up, } \\
\text { oedematous }\end{array}$ & 8 & $4.37 \%$ & 11 & $68.75 \%$ \\
\hline 2. & $\begin{array}{c}\text { Ballooned out lower } \\
\text { uterine segment }\end{array}$ & 3 & $1.63 \%$ & 5 & $31.25 \%$ \\
\hline 3. & Uterine atony & 5 & $2.71 \%$ & 5 & $31.25 \%$ \\
\hline 4. & $\begin{array}{c}\text { Uterine/Vesical } \\
\text { laceration }\end{array}$ & Nil & Nil & Nil & Nil \\
\hline 5. & $\begin{array}{c}\text { Injury to abdominal } \\
\text { viscera }\end{array}$ & Nil & Nil & Nil & Nil \\
\hline
\end{tabular}

Percentage of intra operative complications were more in cesarean sections done in second stage compared to cesarean section done in first stage.

Table 4: Post Operative Complications Of Cesarean Section

\begin{tabular}{|c|c|c|c|c|c|}
\hline S. & Type of \\
No & Complications & \multicolumn{2}{|c|}{$\begin{array}{c}\text { Cases in first Stage } \\
\text { cases }\end{array}$} & \multicolumn{2}{|c|}{ Cases in second stage } \\
\hline 1 & $\begin{array}{c}\text { Post partum } \\
\text { Hemorrhage }\end{array}$ & 1 & $0.54 \%$ & 1 & $6.25 \%$ \\
\hline 2 & $\begin{array}{c}\text { Wound } \\
\text { Infection }\end{array}$ & 10 & $5.43 \%$ & 1 & $6.25 \%$ \\
\hline 3 & $\begin{array}{c}\text { Post operative } \\
\text { blood } \\
\text { Transfusions }\end{array}$ & 22 & $11.9 \%$ & 4 & $25 \%$ \\
\hline 4 & Paralytic ileus & Nil & Nil & Nil & Nil \\
\hline
\end{tabular}

Percentage of post operative complications were more in sections done in second stage compared to first stage.

Table 5: Neonatal Outcome APGAR(1 minute)

\begin{tabular}{|c|c|c|c|c|c|}
\hline S. & 1st minute & \multicolumn{2}{|c|}{$1^{\text {st }}$ stage } & \multicolumn{2}{c|}{$2^{\text {nd }}$ stage } \\
\cline { 3 - 6 } & Apgar & $\begin{array}{c}\text { No. of } \\
\text { cases }\end{array}$ & percentage & No. of cases & Percentage \\
\hline 1. & $<3$ & 3 & $1.64 \%$ & 1 & $6.66 \%$ \\
\hline 2. & $3-5$ & 6 & $3.26 \%$ & 4 & $26.66 \%$ \\
\hline 3. & $5-7$ & 174 & $94.5 \%$ & 9 & $60 \%$ \\
\hline 4. & $>7$ & 1 & $0.5 \%$ & 1 & $6.66 \%$ \\
\hline
\end{tabular}

Neonates delivered in second stage by cesarean section had good APGAR in $60 \%$ of cases compare to $94.5 \%$ of neonates delivered in first stage by cesarean section.

Table 6: Neonatal Outcome APGAR(5 MINUTE)

\begin{tabular}{|c|c|c|c|c|c|}
\hline S. & 5 minute & \multicolumn{2}{|c|}{$1^{\text {st }}$ stage } & \multicolumn{2}{c|}{$2^{\text {nd }}$ stage } \\
\cline { 3 - 6 } No. & Apgar & No. of cases & percentage & No. of cases & Percentage \\
\hline 1. & $<3$ & 1 & $0.5 \%$ & 0 & $0 \%$ \\
\hline 2. & $3-5$ & 3 & $1.6 \%$ & 2 & $13.33 \%$ \\
\hline 3. & $5-7$ & 4 & $2.17 \%$ & 1 & $6.66 \%$ \\
\hline 4. & $7-9$ & 172 & $93.4 \%$ & 11 & $73.33 \%$ \\
\hline 5. & $>9$ & 4 & $2.17 \%$ & 1 & $6.66 \%$ \\
\hline
\end{tabular}

Neonates delivered in second stage by cesarean section had good APGAR in $73.33 \%$ compare to $93.4 \%$ of neonates delivered in first stage cesarean section 


\section{International Journal of Science and Research (IJSR) \\ ISSN (Online): 2319-7064}

Index Copernicus Value (2013): 6.14 | Impact Factor (2015): 6.391

Table 7: Weight Distribution Of Neonates

\begin{tabular}{|c|c|c|c|c|c|c|c|}
\hline \multirow{2}{*}{ S.No. } & \multirow{2}{*}{ Wt. of baby (in kgs) } & \multicolumn{2}{|c|}{$1^{\text {st }}$ stage } & \multicolumn{2}{c|}{$2^{\text {nd }}$ stage } & \multicolumn{2}{c|}{ Total } \\
\cline { 3 - 7 } & & No. of babies & percentage & No. of babies & percentage & No. of babies & percentage \\
\hline 1. & $<2$ & 5 & $2.71 \%$ & 1 & $6.25 \%$ & 6 & $3 \%$ \\
\hline 2. & $2-3$ & 124 & $66.66 \%$ & 9 & $56.25 \%$ & 133 & $66.5 \%$ \\
\hline 3. & $>3$ & 55 & $29.8 \%$ & 6 & $37.5 \%$ & 61 & $30.5 \%$ \\
\hline
\end{tabular}

Neonates delivered in second stage by cesarean section had more than $3 \mathrm{~kg}$ weight in $37.5 \%$ compared to $29.8 \%$ delivered in first stage by cesarean section.

Table 8: NICU Admissions-Indications in Emergency Cesarean Section

\begin{tabular}{|c|c|c|c|c|c|}
\hline \multirow{2}{*}{$\begin{array}{c}\text { S. } \\
\text { No }\end{array}$} & \multirow{2}{*}{ Indications } & \multicolumn{2}{|c|}{$\begin{array}{c}\text { cases admitted in } 1^{\text {st }} \\
\text { stage }\end{array}$} & \multicolumn{2}{c|}{$\begin{array}{c}\text { cases admitted in 2nd } \\
\text { stage }\end{array}$} \\
\cline { 3 - 6 } & & Number & Percentage & Number & Percentage \\
\hline 1 & Birth asphyxia & 4 & $40 \%$ & 3 & $75 \%$ \\
\hline 3 & Low birth Wt & 5 & $50 \%$ & 1 & $25 \%$ \\
\hline 4 & $\begin{array}{c}\text { Neonatal } \\
\text { seizures }\end{array}$ & 1 & $10 \%$ & Nil & Nil \\
\hline 5 & Sepsis & Nil & Nil & Nil & Nil \\
\hline 6 & MAS & Nil & Nil & Nil & Nil \\
\hline
\end{tabular}

$75 \%$ of neonates delivered in second stage by cesarean section had Birth asphyxia compared to $40 \%$ of neonates delivered in first stage by cesarean section

Table 9: Maternal Morbidity in Emergency Cesarean Section in Labour

\begin{tabular}{|c|c|c|c|c|c|}
\hline S. & Out come & \multicolumn{2}{|c|}{ Unfavourable } & \multicolumn{2}{c|}{ Favourable } \\
\cline { 3 - 6 } No & & Number & Percentage & Number & Percentage \\
\hline 1 & First stage & 16 & $8.7 \%$ & 168 & $91.3 \%$ \\
\hline 2 & Second stage & 16 & $100 \%$ & 0 & $0 \%$ \\
\hline
\end{tabular}

Maternal morbidity is statistically highly significant in cesarean sections done in second stage than in first stage. Chi-square value is 84.63 .

P value 0.001 - highly significant.

There is no maternal mortality in this study

Table 10: Perinatal Morbidity in EMLSCESAREAN Section in Labour

\begin{tabular}{|c|c|c|c|c|c|}
\hline $\begin{array}{c}\text { S. } \\
\text { No }\end{array}$ & Outcome & \multicolumn{2}{|c|}{ Unfavourable } & \multicolumn{2}{c|}{ Favourable } \\
\cline { 3 - 6 } & & Number & Percentage & Number & Percentage \\
\hline 1 & First stage & 10 & $5.43 \%$ & 174 & $94.5 \%$ \\
\hline 2 & Second stage & 4 & $25 \%$ & 12 & $75 \%$ \\
\hline
\end{tabular}

Neonates delivered in second stage by cesarean section had statistically significant morbidity than neonates delivered in first stage by cesarean section.

Chi-square value 5.91

P-value $<0.05$ - significant

Table 11: Perinatal Mortality in EM LSCESAREAN Section

\begin{tabular}{|c|c|c|c|c|c|c|}
\hline \multirow[t]{2}{*}{ S.No } & \multirow{2}{*}{\multicolumn{2}{|c|}{ Admissions }} & \multicolumn{2}{|c|}{ Recovered } & \multicolumn{2}{|c|}{ Death } \\
\hline & & & No & Percentage & No & Percentage \\
\hline 1 & $1^{\text {st }}$ stage & 10 & 8 & $80 \%$ & 2 & $20 \%$ \\
\hline 2 & $2^{\text {nd }}$ stage & 4 & 2 & $50 \%$ & 2 & $50 \%$ \\
\hline
\end{tabular}

Percentage (50\%) of mortality was more in Cesarean section done in second stage compared to first stage (20\%).

\section{Discussion}

In this study among the primary cesarean section performed over a period of Two years between Oct 2010-Nov 2012. Incidence of cesarean section done in second stage of Labour was $8 \%$ compared to $12.3 \%$ in the study conducted by Ayhan sucak et al and 8.6\% in Moodly J et al.

Majority of cases $76.4 \%$ were in 20-25 years age group which was comparable to study done by Ritu Gupta et al Where This age group constitutes77\%.

Incidence of cesarean sections in second stage of labour were higher among unbooked cases in81.25\% and in Primigravida75\%, these results were comparable to study done by Ritu Gupta et al where the incidence was 66\%

Specifically for second-stage cesarean section, requires an experienced clinician for pelvic reassessment to re evaluate the degree of moulding of the fetal skull bones and the need to request the woman to bear down in the lithotomy position to rule out and CPD.

CPD was responsible For $56.25 \%$ of cases in which cesarean section was done in second stage .These values were comparable to study done by Ritu Gupta et al where $63 \%$, $67.6 \%$ in study conducted by Shimelis Fantu ${ }^{46}$ et al, 63.3\% in study done by Kabakyenga $\mathrm{Jk}^{47}$ et al.It was $66.3 \%$ in clinical study carried, out by Doshi Haresh Tripathi Jagruti, Maheshwari Sonal, et al

Malpresentations was responsible for obstructed Labour only in $6.25 \%$ of cases because most of the cases of malpresentation operate earlier before reaching the second stage.

Fetal distress was responsible for 38.04\% cases in which section was done in first stage of labour was comparable to $36 \%$ in study conducted by Moodly $\mathrm{J}$ et al.In second stage of labour fetal distress was responsible for $18.7 \%$ of cases of cesarean section is comparable to study conducted by Moodly J et al in which rate was $23 \%$.

Most common Intra operative complication was urinary system injury noted in $68.75 \%$ in Cesarean section done in second stage of labour.All the urinary system injuries were confined to bladder without any ureteral injuries in both groups. The most common bladder injury was the one due to traction resulting in hematuria. Significantly more patients had blood-stained urine in the second-stage than in the firststage Cesarean section and the risk was 4.5 times higher in second-stage women vs first-stage women. Uterine atony in $31.25 \%$ vs $2.71 \%$ in cesarean section done in second and in first stage of labour. 


\section{International Journal of Science and Research (IJSR) \\ ISSN (Online): 2319-7064 \\ Index Copernicus Value (2013): 6.14 | Impact Factor (2015): 6.391}

Patients had PPH in cesarean section done in second stage of labour in $6.25 \%$ patient. Wound infection was noted in $6.25 \%$ patient compared to $0.54 \%$ and $5.43 \%$ in patients underwent cesarean section in first stage of labour. But in studies conducted by Ritu Gupta et al sepsis was $27 \%$.Because of good pre operative Antibiotic coverage there was low incidence of sepsis in our institution. Post operative fever was noted in 1 vs 10 in second stage and first stage cesarean section respectively comparable to 4 vs 10 in study conducted by Moodly J et al.

Neonates delivered in second stage by cesarean section had more than $3 \mathrm{~kg}$ weight in $37.5 \%$ compared to $29.8 \%$ delivered in first stage by cesarean section. $75 \%$ of neonates delivered in second stage by cesarean section had Birth asphyxia compared to $40 \%$ of neonates delivered in first stage by cesarean section.31.25\% of neonates had low 1st minute Apgar compared to $55.7 \%$ of newborns were admitted in the NICU after cesarean section because all had low first minute Apgar score in study conducted by Ritu Gupta et al. Infants born to women who had caesarean section in the second stage of labour, had higher incidence of birth asphyxia, admission to neonatal intensive care unit, sepsis, seizure, need for ventilation and neonatal death .

Neonates delivered in second stage by cesarean section had statistically significant morbidity than neonates delivered in first stage by cesarean section. The present study demonstrates that the cesarean sections performed in the second stage of the labour have significantly higher maternal and neonatal morbidity. The maternal morbidities can be attributed to the difficulty in handling the fetus impacted to the maternal pelvis. The unfavourable neonatal outcomes are probably due to the prolongation of the labour which leads to an inevitable result, hypoxia. Previous studies had also shown adverse outcomes of the neonates when the second stage of the labour is longer than the normal labour.

\section{Summery}

- Incidence of cesarean section done in second stage of Labour was $8 \%$

- Incidence of cesarean sections in second stage of labour were higher among unbooked cases in81.25\%

- Incidence was more in Primigravida75\%

- CPD was responsible For $56.25 \%$ of cases in which cesarean section was done in second stage due to high birth order and un diagnosed CPD till second stage.

- Malpresentations was responsible for obstructed Labour only in $6.25 \%$ of cases because most of the cases of malpresentation operate earlier before reaching the second stage.

- Fetal distress was responsible for $38.04 \%$ cases in which section was done in first stage of labour.

- Most common Intra operative complication was urinary system injury noted in $68.75 \%$ in Cesarean section done in second stage of labour

- . The most common bladder injury was the one due to traction resulting in hematuria. Significantly more patients had blood-stained urine in the second-stage than in the first-stage Cesarean section and the risk was 4.5 times higher in second-stage women vs first-stage women.
- Uterine atony in $31.25 \% \mathrm{vs} 2.71 \%$ in cesarean section done in second and in first stage of labour.

- Patients suffered from PPH in cesarean section done in second stage of labour in $6.25 \%$ patient Compared to $0.54 \%$ in first stage of labour

- Wound infection was noted in $6.25 \%$ patient compared to $5.43 \%$ in patients underwent cesarean section in second stage than that of first stage of labour

- Neonates delivered in second stage by cesarean section had more than $3 \mathrm{~kg}$ weight in $37.5 \%$ compared to $29.8 \%$ delivered in first stage by cesarean section.

- $75 \%$ of neonates delivered in second stage by cesarean section had Birth asphyxia compared to $40 \%$ of neonates delivered in first stage by cesarean section.

- Neonates delivered in second stage by cesarean section had good APGAR in $73.33 \%$ compare to $93.4 \%$ of neonates delivered in first stage cesarean section

- Maternal morbidity is statistically highly significant in cesarean sections done in second stage than in first stage.

- Neonates delivered in second stage by cesarean section had statistically significant morbidity than neonates delivered in first stage by cesarean section

- Percentage (50\%) of mortality was more in Cesarean section done in second stage compared to first stage (20\%).

\section{Conclusion}

1) In the study,87.5\% of the cases were unbooked cases in which section was done in second stage of Labour.

2) Fetal distress(38.04\%) was most common indication for section done in first stage of labour due to more number of inductions

3) Most common indication for cesarean section done in second stage of labour was undiagnosed CPD(56.25\%).

4) Intra operative complications were more in sections done in second stage compared to first stage of labour.

5) Maternal morbidity and Perinatal morbidity, mortality was more in sections done in Second stage than in first stage of labour

6) Improvement of obstetrics services in periphery and use of partogram and early referral of cases can reduce the maternal and perinatal morbidity and mortality.Proper assessment of cases and cesarean section done at appropriate time can reduce maternal and perinatal mortality and morbidity.

7) In case of second stage cesarean sections,neonatal weight of $>3 \mathrm{~kg}$ was observed. Hence,clinical and sonological estimation of fetal weight can reduce the second stage cesarean section rate.

8) The presence of experienced obstetrician and neonatologist at the time of delivery can reduce the perinatal mortality and morbidity.

9) Careful fetal heart rate monitoring and progression of labour can reduce the rate of cesarean section in the second stage of labour.

10)In conclusion, decision to delivery interval should be reduced to decrease maternal and perinatal mortality and morbidity. 


\section{International Journal of Science and Research (IJSR) \\ ISSN (Online): 2319-7064 \\ Index Copernicus Value (2013): 6.14 | Impact Factor (2015): 6.391}

\section{References}

[1] Notzon, F. C., S. Cnattingius, P. Bergsjo, S.Cole, S.Taffel, L. Irgens, A. K. Daltveit, Am. J. Obstet. Gynecol., 170(1994)495.

[2] Landon,M. B., J. C. Hauth, K. J. Leveno, C. Y. Spong, S. Leindecker, M.-W. Varner, A. H. Moawad, N. Engl. J. Med., 351(2004) 2581

[3] Chauhan, S. P., J. N. Martin Jr., C. E. Henrichs,J. C. Morrison, E. F. Magann, Am. J. Obstet Gynecol., 189 (2003)408.

[4] Gabert, H. A., M. Bey, Obstet. Gynecol. Clin. North. Am., 15(1998) 591.

[5] Amirikia, H., B. Zarewych, T. Evans, Am. J. Obstet.Gynecol., 104 (1991) 81

[6] Jolly J, Walker J, Bhadra K. Subsequent obstetric performance related to primary mode of delivery.Br J obstetric Gynecol 1999;106(3):277-32.

[7] Robson M. Can the high cesarean section rates be reduced. Recent Advances Obstet Gynaecol 2003;22(6):71-83.

[8] Irion O, Morales MA, Faltin D. Epidemic of cesarean section: A necessary evil. Rev Med Suisse 2005;1(6):2566-9

[9] Varela FR, Vazquez RH, Menacker F, Ahmed Y, Grant AM, Jamieson DJ. Rates of cesarean delivery among Puerto Rican women. Puerto Rico and the US main land 1992-2002. Morbidity and mortality weekly report 2006;55(3):68-71.

[10] Kombo I, Bedi N, Dhillos BS et al. A critical appraisal of cesarean section rates at teaching hospitals in India. Int J Gynaecol obstet 2002;151-8.

[11] Sreevidya S, Sathiyasekaran BW.High cesarean rates Madras (India):a population based cross sectional study.BJOG2003;110:106-11.

[12]D. S. Gifford, S. C.Morton, M. Fiske, J. Keesey, E. Keeler, and K. L. Kahn, "Lack of progress in labor as a reason for cesarean, "Obstetrics and Gynecology, vol. 95, no. 4, pp. 589-595, 2000.

[13] S. L. Seal, G. Kamilya, J. Mukherji, S. K. Bhattacharyya, A. De, and A. Hazra, "Outcome in second- versus first-stage cesarean delivery in a teaching institution in Eastern India," American Journal of Perinatology, vol. 27, no. 6, pp. 507-512, 2010.

[14]D. Selo-Ojeme, S. Sathiyathasan, and M. Fayyaz, "Caesarean delivery at full cervical dilatation versus caesarean delivery in the first stage of labour: comparison of maternal and perinatal morbidity," Archives of Gynecology and Obstetrics, vol. 278, no.3, pp. 245-249, 2008.

[15] K. C. Winovitch, D. A. Wing, D. C. Lagrew, and J. H. Chung,"The risk of acute neonatal morbidities in the delivery room after primary cesarean at term: influence of labor and stage, "American Journal of Perinatology, vol. 26, no. 8, pp. 545-551,2009.

[16] Schneider, H., Am. J. Obstet. Gynecol., 205 (2001) 205.

[17] Catherine, Deneux-Tharaux, Elodie, Carmona, Gerard, Breart et al. Post partum maternal mortality and cesarean delivery. Obstet Gynecol 2006; 108:541-48.

[18] Steven, Bloom, Catherine, Sponge. Complications of anesthesia for cesarean section. Obstet Gynecol 2005; 106:281-87.
[19] S N Mukherjee. Rising cesarean section rate. J Obstet Gynecol India 2006; 56:298-300.

[20] Alexander, James M, Leveno, Kenneth J, Rouse, Dwight $\mathrm{J}$ et al. Comparison of maternal and infant outcomes from primary cesarean delivery during the second compared with first stage of labour. Obstet Gynecol 2007; 109(4): 917-21.

[21] Macara, Lena M, Murphy, Karl W. The contribution of dystocia to the cesarean section rate. Am J Obstet Gynecol 1994; 171(1): 71-77.

[22] V Elve|i-Ga \{parovi\} et al.: Maternal and Fetal Outcome in Caesarean Section, Coll. Antropol. 30 (2006) 1: 113-118.

[23] Doshi Haresh, Tripathi Jagruti, Maheshwari Sonal, et al. Cesarean section -Changing trends- a National survey. J Obstet Gynecol India 2009; 59(2) : 140-3.

[24] Jeffrey L Ecker, Katherine T Chen, Amy P Cohen, et al. Increased risk of cesarean delivery with advancing maternal age. Indications and associated factors among nulliparous women. Am J Obstet Gynecol 2001; 185: 883-7.

[25] Eyal Sheiner, Illana Shohan-Vardi, Reli Hershkovitz, et al. Infertility treatment is an independent risk factor for cesarean section among nulliparous women. Am J Obstet Gynecol 2001; 185: 888-92.

[26] Aaron B Caughey , James M Nicholson, Yvonne W Cheng, et al. Induction of labour and cesarean delivery by gestational age. Am J Obstet Gynecol 2006; 195: 700-5.

[27] Joshua L Weiss, Fergal D Malone, Danielle Emig, et al. Obesity -Obstetrics complications and cesarean delivery rates-A population based screening study. Am J Obstet Gynecol 2003; 190: 402-70.

[28] Gahlot Ajay, Suman A. Spontaneous delivery or manual removal of the placenta during cesarean section. J Obstet Gynecol India 2009; 59(2): 127-30.

[29] Linda J Hefner, James R Scott, Steven G Gabbe .Cesarean delivery on demand. Clinicals Obstet Gynecol 2004; 2:385.

[30]Linda J Hefner, James R Scott, Steven G Gabbe .Cesarean delivery on demand. Clinicals 1Obstet Gynecol 2004; 2: 387.

[31] Elizabeth G Doherly, Eric .C.Eichenwald .Cesarean delivery emphasis on the neonate. Clinical Obstet Gynecol 2004; 2: 332-3.

[32] Jennifer Bailit, Thomas E Love, Neal. V Dawson. Quality of obstetric care and risk adjusted primary cesarean delivery rates. Am J Obstet Gynecol 2005; 194: 402-7.

[33] Cunningham, Leveno, Bloom, et al. cesarean delivery and peripartum hysterectomy. $23^{\text {rd }}$ ed.Williams Obstetrics, Mc Graw Hill Publications 2010; 25: pp 544-62.

[34] Mark B London. Cesarean Delivery, $5^{\text {th }}$ ed, Steven G Gabbe, Jennifer R Neibyl, Joe Leigh Simpson. Obstetrics Normal and Problem Pregnancy. Churchill Livingstone Publications 2007; 19: pp 486 - 517.

[35] CMAJ 176 (4): Liu S, Liston RM, Joseph KS, Heaman M, Sauve R, Kramer MS (2007). "Maternal mortality and severe morbidity associated with low-risk planned cesarean delivery versus planned vaginal delivery at term"455-60. doi:10.1503/cmaj.060870. PMC 1800583. PMID 17296957 
[36] Pai, Madhukar (2000). "Medical Interventions: Caesarean Sections as a Case Study". Economic and Political Weekly 35 (31): 2755-61

[37] "Why are Caesareans Done?". Gynaecworld. Retrieved 2006-07-26.

[38] Rabiu KA, Adewunmi AA, Akinola OI, Eti AE, Tayo AO.Niger Postgrad Med J. 2011 Sep; 18(3):165-71.

[39] Ayhan Sucak, Şevki Çelen, Eren Akbaba, Sunullah Soysal, Ozlem Moraloglu, and Nuri Danışman. Obstetrics and Gynecology International Volume 2011 (2011), Article ID 986506, 4 pages doi:10.1155/2011/986506.

[40] Ritu Gupta, Sanjoy kumar Porwal. In J Biol Med Res.2012; 3(3):2185-2188.

[41] Moodley J, Devjee J, Khedun SM, Esterhuizen T,SA Fam Pract 2009;51(4):328-331

[42] Cebekulu L, Buchmann EJ. Complications associated with caesarean section in the second stage of labour. Int J Gynaecol Obstet 2006; 95:110 14.

[43] Altman MR, Lydon-Rochelle MT. Prolonged second stage of labour and risk of adverse maternal and perinatal outcomes: a systematic review. Birth 2006; 33(4):315-322

[44] Alexander JM, Leveno KJ, Rouse DJ, et al. Comparison of maternal and infant outcomes from primary caesarean delivery during the second compared with first stage of labour. Obstet Gynecol 1007; 109(4):91721. .

[45] Allen VM, O'Connell CM, Baskett TF. Maternal and perinatal morbidity of caesarean delivery at full cervical dilatation compared with caesarean delivery in the first stage of labour. $\mathrm{Br} \mathrm{J}$ Obstet Gynaecol 2005; 112(7):986-90.

[46] Shimelis Fantu (MD), Hailermanariam Segni (MD), Fessahaye Alemseged MD (MPHE). Incidence, causes and outcome of obstructed labour in Jimma University Specialized Hospital. Ethiop J Health Sci. 2012 Nov; 20(3):145-151.

[47] Jerome K Kabakyenga, Per-olof Ostergren, Eleanor et al. Individual and health facility factors and the risk for obstructed labour and its adverse outcomes in south western Uganda. BMC Pregnancy childbirth.2011 Oct $14 ; 11: 73$. 